\title{
El rechazo a vacunar a los niños: un desafío por enfrentar
}

\author{
Refusal to have children vaccinated: A challenge to face
}

\author{
Dr. Pablo Ricardo Justich
}

\begin{abstract}
RESUMEN
Lasinmunizaciones constituyen una herramienta fundamental en la salud pública. No obstante hay un grupo considerable de individuos que deciden no vacunarse o no vacunar a sus hijos. Los médicos que indican no vacunar (a personas que tienen indicación de vacunarse), en contra de programas oficiales de vacunación, contradicen sólidas evidencias científicas y se exponen a riesgos médico-legales por su prescripción. Los padres que deciden no vacunar a sus hijos lo hacen bajo convicciones ideológicas, religiosas, modas o esnobismo, etc. y su decisión les quita una defensa epidemiológica a sus hijos susceptibles de contraer la enfermedad.

Los efectos sanitarios de esta corriente son nocivos para esos niños y para la comunidad. La educación y la correcta comunicación con la población, la vigilancia epidemiológica y de efectos adversos, un marcolegal claro respecto de las responsabilidades, derechos y obligaciones, el consentimiento informado de no vacunación, etc., son herramientas que pueden ayudar a erradicar esta conducta. La mejor forma de evitar los efectos adversos de las vacunas es erradicar la enfermedad y que la vacuna ya no sea necesaria. Palabras clave:vacunación, enfermedad, prevención y control, cobertura vacunal, inmunidad de grupo.
\end{abstract}

http:/ /dx.doi.org/10.5546/aap.2015.443

\section{INTRODUCCIÓN}

Cuando a fines del siglo XIX y principios del siglo XX las epidemias de poliomielitis, viruela, sarampión, etc., diezmaban poblaciones enteras al causar muertes o graves secuelas, pocos podrían imaginar que solo unas décadas después se comenzaría a plantear su erradicación. Las mejoras en las condiciones de vida, y fundamentalmente la incorporación de las inmunizaciones como una herramienta sanitaria, en un marco de acción conjunta y coordinada de los sistemas de salud por sobre las fronteras de las naciones, produjeron una verdadera revolución en el cuidado de la salud.

La viruela ya ha sido erradicada en todo el planeta, igual que la poliomielitis en vastas regiones y, con respecto al sarampión, la Organización Mundial de la Salud (OMS) calcula en 15,3 millones las muertes evitadas entre el año 2000 y el año 2013 gracias a la vacunación. ${ }^{1}$ En este contexto y con las herramientas disponibles, parece evidente que la erradicación definitiva de estas y otras enfermedades infectocontagiosas está a nuestro alcance.

No obstante, así como también lo estaba lograr una "salud para todos en el año 2000" y hoy la realidad dista mucho de ello, la posibilidad de terminar con este flagelo que representan las enfermedades inmunoprevenibles también se ve amenazada por el advenimiento de corrientes de pensamiento que anteponen ciertas prerrogativas individuales en conflicto con el bienestar general.

Afortunadamente, la mayoría de la población comprende que el cumplimiento de las pautas oficiales de inmunización es el camino correcto para mejorar la salud de la población infantil, pero como queda reflejado con las epidemias de sarampión ocurridas en los últimos años, hay aspectos que deben ser corregidos para lograr los objetivos planeados.

La relación entre los riesgos y los beneficios de las vacunas contra la poliomielitis y la triple vacuna contra sarampión-rubeola-parotiditis no resiste ninguna discusión desde el punto de vista médico y epidemiológico. No obstante, existe un grupo poblacional que toma la susceptibilidad como una opción favorable y también la difunde bajo premisas muy discutibles. En vista de la aceptación que tiene esta postura, no solo en poblaciones sin acceso 
a una información suficiente, sino también en grupos sociales con máximo grado de instrucción, debemos encarar este problema tratando de comprender las razones que llevan a esta elección para poder elaborar una estrategia más eficaz.

\section{EPIDEMIOLOGÍA}

Importancia. Para poder comprender la importancia de abordar el problema de la negativa de vacunar a los niños, vamos a definir algunos conceptos básicos. La poliomielitis era la principal causa de parálisis fláccida infantil hasta la generalización del uso de la vacuna. Si bien no tiene cura, existen vacunas de probada eficacia en su prevención. ${ }^{2}$ El sarampión continúa siendo una de las principales causas de muerte evitable en niños pequeños, pese a existir una vacuna de probada eficacia. Más allá de las características propias de cada enfermedad, sabemos que, para que la circulación de un virus salvaje se interrumpa, debemos lograr la máxima reducción de la proporción de personas susceptibles. ${ }^{3}$ Esto se puede conseguir mediante estrategias adecuadas, recursos suficientes y colaboración de los Gobiernos y poblaciones. También sabemos que, una vez lograda una cobertura extensa, cada paso necesario para ampliarla demanda mayores costos y esfuerzos.

Susceptibilidad. Existen, para las enfermedades inmunoprevenibles, distintos grupos con susceptibilidad a padecerlas. En primer lugar, están los que no pueden recibir la vacuna (por edad o patología de base, falta de acceso a sanidad, etc.) y aquellos que, aun vacunados, persisten en la misma condición (fallo primario de vacuna, falta de respuesta inmunológica, etc.). Estos representan un desafío sanitario porque, por un lado, son los más vulnerables ante un brote y, por otro, son el terreno potencial para que persista la circulación de virus.

En segundo lugar, fuera de esta cohorte de individuos involuntaria o inevitablemente susceptibles, se agrega una que podríamos definir de "vulnerabilidad electiva" (o infligida, en cuanto a los menores de edad). En este caso particular, existe una elección, algunas veces, basada en la prescripción profesional y, otras, basada en convicciones, religión, ideología, etc. Como resultado, hay un grupo de individuos, a veces en proporciones preocupantes, que hacen valer su elección por sobre los beneficios colectivos de la inmunización masiva. Esto es posible gracias a la fuerte difusión que tiene, en ciertos grupos sociales, la falsa consigna de que los riesgos de la vacunación superan los de la susceptibilidad. Las consecuencias de esta decisión suelen estar transitoriamente atenuadas por la masiva aceptación de las inmunizaciones por parte de la población, lo que permite establecer una frontera epidemiológica basada en la "inmunidad de grupo".

Inmunidad de grupo. Es la protección que la población posee frente a una infección debido a la presencia de individuos inmunes a ella. ${ }^{4}$ Este efecto colectivo es proporcional al nivel de inmunización de la población, ya sea por haber padecido la enfermedad o por la vacunación. Posee un efecto beneficioso al reducir la posibilidad de circulación del virus y protege a los susceptibles. Este efecto se reduce cuando crece la proporción de no inmunes en relación con los inmunes (Figura 1). Este instrumento que permite proteger a los susceptibles "involuntarios" corre peligro cuando se valen de él también una cantidad creciente de susceptibles "electivos", ya que no han sido vacunados. ${ }^{5-7}$ Se agrega el problema de que las familias reacias a las vacunas tienden a agruparse según creencias o pertenencia a grupos, lo que genera un fenómeno de "cluster" o "racimo", que aumenta los riesgos de vulnerarla. ${ }^{8}$

\section{¿POR QUÉ NO VACUNAR?}

a) ¿Por qué no vacunar a mis pacientes?

\section{Los médicos que indican no vacunar.}

Esta situación es muy compleja, ya que genera un debate profundo entre el libre albedrío que desea tener el médico en sus elecciones y el carácter normativo que poseen los programas de inmunizaciones. El médico que, a partir de la construcción de su conocimiento, cree que las vacunas pueden ser más perjudiciales que la enfermedad suele actuar bajo convicciones honestas, aunque, sin duda, erróneas. De hecho, algunas corrientes de la homeopatía sostienen posturas de esta índole. La discusión sobre cuánto de arte y cuánto de ciencia tiene nuestra profesión puede conducirnos a perjudiciales errores dialécticos.

Es importante que, desde la salud pública, podamos hacerle llegar a la población y al personal sanitario que la sistematización de las vacunas no surge de una pretensión hegemónica, sino de un análisis profundo de los riesgos y los beneficios de esta práctica. Así, como hay numerosos avales de gran rigor académico y estadístico, debemos ofrecer a quienes proponen 
no vacunar que participen de este debate con instrumentos científicamente aceptados. El monitoreo sistemático de los efectos adversos, su estudio profundo y la vigilancia epidemiológica deben ser transparentes y accesibles para poder ponerles valor real a las sólidas evidencias científicas en contraposición al concepto de que su utilidad es un mito.

Otro hecho que no debemos dejar de contemplar es que nuestras responsabilidades como médicos exceden los actos médicos individuales en la medida que puedan tener repercusión comunitaria. Si todos permitiéramos que el interés individual superara el interés colectivo, no existiría la salud pública y los efectos serían devastadores.

Por último, debemos contemplar en estas circunstancias aspectos bioéticos y también médico-legales. La construcción del marco legal de las políticas públicas de inmunizaciones se basa en aplicar una técnica de demostrada eficacia y efectividad clínica, que aun sopesando sus riesgos, constituye una solución contundente a un problema sanitario concreto. El objetivo de estas políticas es poner el bien común por sobre toda objeción. De este modo, cuando un Estado define su calendario oficial, tiene un valor normativo o de ley (en Argentina, la Ley 22909 13/09/1983). ${ }^{9}$ Atendiendo a ello, la recomendación de un profesional matriculado, en ejercicio legal de su profesión, no debería ser contraria.
Ahora cabría preguntarnos: ¿hay mala praxis en la recomendación de no vacunar? En principio, no, porque no hay un daño comprobado y atribuible a esa decisión. Sin embargo, en el caso de un brote y ante la ocurrencia de una muerte o secuela, seguramente, pueda demostrarse inobservancia de los reglamentos o deberes a su cargo con apartamiento de la normativa legal aplicable e, incluso, negligencia. Es aquí donde el poder judicial, las autoridades sanitarias, las sociedades científicas y las universidades deben comprometerse con mensajes claros.

\section{b) ¿Por qué promociono la no vacunación?}

Existen múltiples personas u organizaciones que proponen y difunden el efecto nocivo de las vacunas y las supuestas ventajas de no vacunar. Hay explicaciones religiosas, ideológicas, conspirativas, etc. Tan plurales son estas opiniones como poco rigurosas en su análisis biológico y epidemiológico. Su diversidad es fruto de la accesibilidad y multiplicación que tiene la información en un medio poco controlado, como es internet. Las acciones directas sobre estos foros no tienen sentido legal y nos expondrían a quedar como censores de la libertad de expresión. Diferente es el caso de las publicaciones científicas, en las que debemos exigir rigor metodológico y responsabilidad, en especial en temas de alto impacto sanitario. Lo más importante, seguramente, sea analizar por

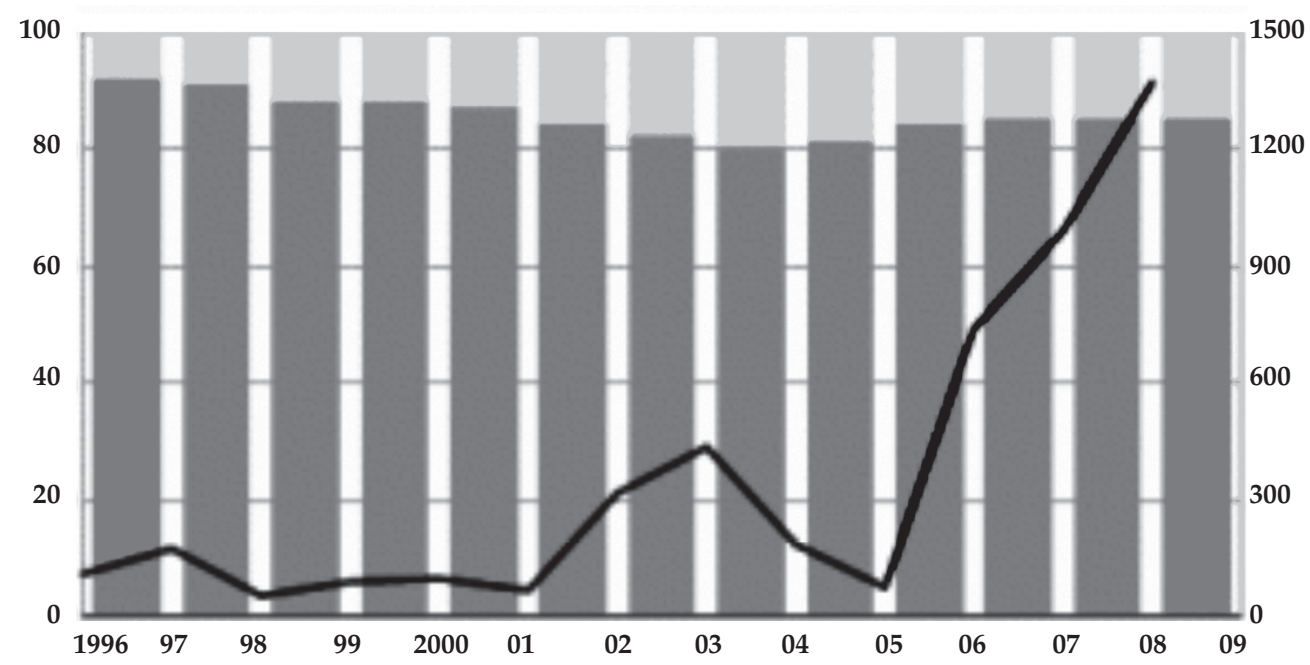


qué razón estas posturas poseen tal predicamento en la población.

\section{c) ¿Por qué no acepto vacunar a mis hijos?}

En esta decisión, existen múltiples causas: creencias religiosas, información errónea, falta de conocimientos, moda o esnobismo, naturismo radical, ideología, etc. En un mundo que tiende a ponderar la diversidad y la libertar de opinión, es lógico pensar que esta se exprese en todos los órdenes de la vida.

También hay que considerar la falsa asociación creada por la publicación de artículos de escaso rigor científico, entre el timerosal empleado en algunas vacunas y el autismo. Esto, que ha sido rebatido de modo claro y contundente ante la comunidad científica, ha dejado huellas en la población, que no siempre accede a las rectificaciones publicadas. ${ }^{10}$

A esto debemos agregar una situación más actual: hay sectores (cada vez más amplios) de la población que desconfían de los intereses comerciales de las empresas productoras de vacunas. La difusión de publicidad no siempre correcta desde el punto de vista ético orienta a pensar que, muchas veces, se magnifican los problemas para incitar la compra de vacunas. Cabría pensar si este tipo de publicidades no debiera limitarse o suprimirse. Las inmunizaciones sobre patologías de alto impacto quizás deberían ser una cuestión de Estado más que una decisión comercial.

Ante un número preocupante de personas que optan por no vacunar a sus hijos, es errado ignorarlas. Sin justificar sus razones, el primer paso es intentar entender por qué su mejor opción es un riesgo y, de esa forma, tratar de mejorar nuestras respuestas a sus interrogantes.

\section{CONSECUENCIAS DE LA NO VACUNACIÓN}

Como consecuencia de la elección de no vacunar, nos enfrentamos a múltiples cuestiones que no debemos perder de vista. En primer lugar, la posibilidad de ese niño de padecer la enfermedad o, incluso, morir. En segundo lugar, perpetuar canales de transmisión que aumenten los riesgos no solo de ese paciente, sino también de aquellos susceptibles "involuntarios" de enfermar, que pueden morir por esta causa. En tercer lugar, la negación a vacunar permite que una decisión individual, si se multiplica, atente contra las posibilidades de erradicación de la enfermedad, que, como ya señalamos, es uno de los logros más trascendentes de la medicina preventiva. Por último, cerrar las puertas a que sus propios hijos o nietos puedan algún día dejar de vacunarse si logramos erradicar estas enfermedades. Todo esto sin mencionar los costos en vidas, esfuerzos sanitarios y económicos que las sociedades enfrentan cuando las epidemias persisten.

\section{Algunas cuestiones para el debate:}

- ¿Pueden los padres ser libres de tomar la decisión de no vacunar a sus hijos?

- ¿Son realmente las vacunas una contradicción con una vida natural y saludable?

- ¿No estaremos perdiendo la batalla dialéctica?

\section{Propuestas para enfrentar este problema}

- Educar y comunicar. En primer lugar, y ante la falta de evidencias científicas que demuestren que las vacunas representan un riesgo mayor al que previenen, debemos entender que estamos ante un emergente de tipo cultural. Por lo tanto, la primera respuesta tiene que ser la educación. Sin pretender ser dueños de una verdad única, es nuestra obligación brindar un mensaje claro sobre la política de inmunizaciones, sus logros y metas. Debemos demostrar que la salud de una comunidad es una responsabilidad colectiva, en la cual la población no es solo beneficiaria, sino protagonista del proceso. Es importante dar un debate serio y con argumentos claros en el consultorio y en toda la red de instituciones y organizaciones intermedias que participan del proceso sanitario y también educativo. En una sociedad solidaria y bien informada, podríamos aceptar que "si se cree en los principios de la vacunación, no se debe temer a la libertad individual para aceptarla". ${ }^{11}$

- Vigilancia epidemiológica. Debemos demostrar a la comunidad científica y a la población general que los mecanismos de vigilancia, tanto de enfermedades como de efectos adversos de las vacunas, son instrumentos serios y eficaces, y no responden a intereses ajenos a la salud pública.

- La ley al servicio de la salud. Hay leyes claras respecto de la obligatoriedad de vacunar a los niños. Estas deben constituirse en una herramienta fundamental del Estado para anteponer los intereses de la comunidad por sobre las elecciones individuales, máxime si carecen de sustento científico. Asimismo, el mensaje de la justicia debe ser claro y 
contundente, en especial hacia los que prescriben la no vacunación sin justificarla y explicitando la responsabilidad que tendrían los padres que les niegan el derecho a vacunarse a sus hijos sobre los daños que esto podría causar a ellos y a su entorno.

- Estado y derechos. Las vacunas son un derecho y una obligación. Es habitual la exigencia del cumplimiento del plan de vacunas para acceder a la escolarización, beneficios sociales, etc. Esto no solo está hecho para garantizar la vacunación a los niños, sino también para asegurarse que, en las instituciones escolares, se proteja a los susceptibles. Esto podría generar la contradicción de que la víctima de la no vacunación se revictimizara al excluirse de estos beneficios, pero hay que explicar a los padres que esto es resultado de su elección y puede ser revertido aceptándola. Se podría proponer la evicción escolar selectiva de los no inmunizados durante situaciones de riesgo. ${ }^{12}$

- Política y vacunas. Si las inmunizaciones constituyen una herramienta de interés público, deberían cumplir ciertas consignas en relación con su investigación, producción, comercialización y publicidad. La difusión de información sobre enfermedades y secuelas, con la promesa del efecto salvador por parte de vacunas que tienen un costo difícil de asumir por gran parte de la población, crea una situación que, por un lado, puede resultar extorsiva y, por otro, genera sensación de discriminación social entre quienes pueden pagarla y los que no. Esto, además, deteriora la confianza de la población en las inmunizaciones.

- Consentimiento informado. Podría establecerse, a nivel oficial, un modelo de consentimiento informado que deban firmar los tutores que nieguen el derecho a sus hijos, en el que se expliquen claramente los riesgos a los que los exponen y también al resto de la comunidad. Se debe aclarar que este acto implica la posibilidad de asumir las responsabilidades penales y civiles ante el contagio, secuela o muerte del niño o de los contactos que pudieran contagiarse por su intermedio.

\section{CONCLUSIONES}

Si hoy nos planteamos el tema de este artículo, es precisamente por el éxito de las vacunas, que nos hacen percibir los riesgos de estas enfermedades como lejanos o infrecuentes. ¿Qué pasaría ante una hipotética epidemia de ébola, si existiese una vacuna eficaz y segura, como la antisarampionosa? ¿Habría tantas personas que temerían más a la vacuna que a la enfermedad? $\mathrm{Y}$, asimismo, comparando con otros tratamientos, ¿negaríamos que nos administraran antibióticos ante una sepsis bacteriana por temor a sus efectos adversos? Esta es una de las bases que podemos usar en nuestro discurso del día a día con nuestros pacientes que temen vacunarse.

Tenemos ante nosotros nuevos y complejos retos, que debemos afrontar como "aldea humana" más que como individuos que coexisten o compiten. Cuando logremos erradicar el sarampión, la polio, etc., van a desaparecer también los efectos adversos de las vacunas, tal como pasó con la vacuna antivariólica. Este legado constituye una obligación moral de nuestra generación para con la siguiente. Emprender la salud como una construcción colectiva con impacto universal es un imperativo ético que nos hace mucho más fuertes que si actuamos regidos por intereses individuales.

\section{Agradecimiento}

Al personal del Centro de Salud y Acción Comunitaria $\mathrm{N}^{o} 5$ de Ciudad Oculta, Ciudad de Buenos Aires, donde se aprende y se enseña que la salud se construye con esfuerzo y generosidad, aun en las condiciones más difíciles.

\section{REFERENCIAS}

1. Organización Mundial de la Salud. Sarampión. Nota descriptiva $N^{\circ} 286$. Ginebra, 2015. [Acceso: 11 de marzo de 2015]. Disponible en: http://www.who.int/mediacentre/ factsheets/fs286/es/.

2. Organización Mundial de la Salud. Poliomielitis. Nota descriptiva $N^{\circ} 114$. Ginebra, 2014. [Acceso: 16 de marzo de 2015]. Disponible en: http:/ / www.who.int/mediacentre/ factsheets/fs114/es/.

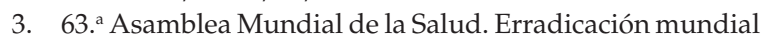
del sarampión: informe de la Secretaría. Ginebra: Organización Mundial de la Salud; 2010. [Acceso: 30 de marzo de 2015]. Disponible en: http:/ /apps.who.int/iris/ bitstream/10665/4880/1/A63_18-sp.pdf?ua=1.

4. Arrazola Martínez MP, de Juanes PardoJR, García de Codes Ilario A. Conceptos generales. Calendarios de Vacunación sistemática del niño y del adulto en España. Impacto de los programas de vacunación. Enferm Infecc Microbiol Clin 2015;33(1):58-65.

5. Vaqué Rafart J. Inmunidad de grupo. Significado e importancia. Revista clínica electrónica en atención Primaria. 2005;8. [Acceso: 28 de marzo de 2015]. Disponible en: http://www.fbjoseplaporte.org/rceap/articulo2. php?idnum=8\&art=01.

6. Comin D. Vacunas: El riesgo de la pérdida de la inmunidad degrupo. Autismodiario. 2011. [Acceso:30 demarzo de 2015]. 
Disponible en: http://autismodiario.org/2011/10/05/ vacunas-el-riesgo-de-la-perdida-de-la-inmunidad-degrupo/.

7. Arrazola Martínez MP, de Juanes Pardo JR. Inmunidad colectiva o de grupo. En: Asociación Española de Pediatría, ed. Manual de vacunas. $4^{\text {ta }}$ ed. Bilbao: AEP;2008:97-105. [Acceso: 16 de marzo de 2015]. Disponible en: http:// vacunasaep.org/manual/Cap3_6_Inmunidad_de_grupo. pdf.

8. Gostin LO. Law, ethics, and public health in the vaccination debates: politics of the measles outbreak. JAMA 2015;313(11):1099-100.
9. Ley 22909. Argentina. Ministerio de Salud de la Nación. Dirección Nacional de Control de Enfermedades Inmunoprevenibles. Buenos Aires, Argentina, 13 de septiembre de 1983. [Acceso: 30 de marzo de 2015]. Disponible en: http://www.msal.gov.ar/dinacei/index. $\mathrm{php} /$ institucional/marco-legal/361-ley-22909.

10. Artigas-Pallarés J. Autismo y vacunas: ¿punto final? Rev Neurol 2010;50(Supl 3):S91-9.

11. Sánchez-Ramón S, Fernández-Cruz E. Reflexión bioética sobre la inmunización de masas en Europa. Inmunología 2006;25(1): 67-71.

12. Yang YT, Silverman RD. Social distancing and the unvaccinated. N Engl J Med 2015;372(16):1481-3. 